\title{
Tinjauan Keberkesanan Program Keusahawanan di Universiti Kebangsaan Malaysia (UKM) terhadap Kebolehpasaran Graduan Menurut Perspektif Alumni UKM
}

\section{(Review of the Effectiveness of Entrepreneurship Program at Universiti Kebangsaan Malaysia (UKM) on Graduate Employment from the Perspective of UKM Alumni)}

\author{
Akmal Sabarudin ${ }^{*}$ (D), Nur Hannan Lokman², Nahzatush Simaa Jantan², \\ Nurul Ashikin Zainrudin, Alis Syazmim Abdul Halim55, Muhamad Azry Khoiry6 id \\ 1Program Pengimejan Diagnostik \& Radioterapi, Fakulti Sains Kesihatan, Universiti Kebangsaan \\ Malaysia, Kampus Jalan Raja Muda Abd Aziz, Kuala Lumpur, Malaysia; \\ Pusat Pembangunan Keusahawanan dan EKS UKM (UKM-CESMED), Universiti Kebangsaan Malaysia \\ (UKM), 43600, Bangi, Selangor, Malaysia. \\ Email: akmal.sabarudin@ukm.edu.my \\ 2Pusat Pembangunan Keusahawanan dan EKS UKM (UKM-CESMED), Universiti Kebangsaan Malaysia \\ (UKM), 43600, Bangi, Selangor, Malaysia. \\ Email: nurhannanlokman@gmail.com \\ ${ }^{3}$ Pusat Pembangunan Keusahawanan dan EKS UKM (UKM-CESMED), Universiti Kebangsaan Malaysia \\ (UKM), 43600, Bangi, Selangor, Malaysia. \\ Email: cmaa@ukm.edu.my \\ 4Pusat Pembangunan Karier UKM (UKM-Karier), Universiti Kebangsaan Malaysia (UKM), 43600, Bangi, \\ Selangor, Malaysia. \\ Email: nurul ashikin@ukm.edu.my \\ 5Pusat Inovasi \& Pemindahan Teknologi (INOVASI@UKMTM), Universiti Kebangsaan Malaysia (UKM), \\ 43600, Bangi, Selangor, Malaysia. \\ Email: alissyazmim@ukm.edu.my \\ 6Jabatan Kejuruteraan Awam, Fakulti Kejuruteraan \& Alam Bina, Universiti Kebangsaan Malaysia \\ (UKM), 43600, Bangi, Selangor, Malaysia; \\ Pusat Pembangunan Keusahawanan dan EKS UKM (UKM-CESMED), Universiti Kebangsaan Malaysia \\ (UKM), 43600, Bangi, Selangor, Malaysia. \\ Email: azrykhoiry@ukm.edu.my
}

\author{
CORRESPONDING \\ AUTHOR (*): \\ Akmal Sabarudin \\ (akmal.sabarudin@ukm.edu.my) \\ KATA KUNCI: \\ Keusahawanan \\ Program keusahawanan \\ Universiti \\ Alumni \\ Mahasiswa- mahasiswi \\ KEYWORDS: \\ Entrepreneurship \\ Entrepreneurship programs
}

\begin{abstract}
ABSTRAK
Penglibatan pelajar untuk menceburi bidang keusahawanan di kampus sangat rendah kerana kurang keyakinan terhadap program yang dianjurkan oleh pihak universiti. Justeru itu, kajian ini dilakukan untuk mendapatkan maklum balas mengenai program keusahawanan di Universiti Kebangsaan Malaysia (UKM) menurut perspektif alumni usahawan UKM. Seramai 15 orang alumni UKM telah terlibat dalam perbincangan kumpulan terfokus untuk membincangkan perancangan, pelaksanaan dan impak program keusahawanan di kampus. Kajian mendapati bahawa program-program keusahawanan banyak memberi impak kepada alumni sehingga mereka berjaya membina karier sebagai usahawan selepas tamat pengajian. Namun begitu, masih terdapat kelemahan dan penambahbaikan yang perlu diberi perhatian terhadap program
\end{abstract}


University

Alumni

Students

CITATION:

Akmal Sabarudin et al. (2022). Tinjauan Keberkesanan Program Keusahawanan di Universiti Kebangsaan Malaysia (UKM) terhadap Kebolehpasaran Graduan

Menurut Perspektif Alumni UKM. Malaysian Journal of Social Sciences and Humanities (MJSSH), 7(2), e001272.

https://doi.org/10.47405/mjssh.v7i2.1272

keusahawanan bagi menarik minat lebih ramai mahasiswamahasiswi menyertai program tersebut. Para alumni juga sudi untuk berkongsi pengalaman dalam program keusahawanan yang bakal dilangsungkan selain melakukan aktiviti perniagaan secara 'hands-on' dan bukan teori semata-mata. Kesimpulannya, kerjasama antara universiti dan usahawan alumni adalah penting bagi memastikan kelestarian program keusahawanan kekal relevan dengan arus generasi masakini.

ABSTRACT
The involvement of students to venture into
entrepreneurship on campus is very low due to lack of
confidence in the programs organized by the university.
Therefore, this study was conducted to obtain feedback on
the entrepreneurship program at Universiti Kebangsaan
Malaysia (UKM) according to the perspective of UKM
entrepreneur alumni. A total of 15 UKM alumni were
involved in focus group discussions to discuss the planning,
implementation and impact of entrepreneurship programs
on campus. The study found that entrepreneurship
programs have a lot of impact on alumni until they
successfully build a career as an entrepreneur after
graduation. However, there are still weaknesses and
improvements that need to be given attention to the
entrepreneurship program to attract more students to
participate in the program. The alumni are also willing to
share their experiences in the entrepreneurship program
that will be held in addition to doing business activities
hands-on and not just theory. In conclusion, cooperation
between universities and alumni entrepreneurs is
important to ensure the sustainability of entrepreneurship
programs remain relevant to the current generation.

Sumbangan/Keaslian: Kajian ini telah menghasilkan formula baharu dalam bentuk perancangan program keusahawanan melibatkan komponen praktikal berserta bimbingan mentor usahawan bagi memastikan keberkesanan dan impak yang tinggi dapat dirasai oleh pelajar yang mengikuti program-program keusahawanan dalam kampus.

\section{Pengenalan}

Kekangan peluang pekerjaan dalam pelbagai sektor yang ditawarkan kepada graduan merupakan masalah utama yang menjadi kerisauan dalam kalangan graduan institusi pengajian tinggi mahupun pihak institusi pengajian sendiri. Graduan dibelenggu dengan masalah pengangguran meskipun mempunyai kelulusan akademik yang baik. Melalui kajian yang telah dijalankan oleh Yusof et al. (2013), pelajar prasiswazah perlu meningkatkan lagi kebolehpasaran mereka dengan menambah kemahiran dan kebolehan diri untuk menghadapi persaingan mendapatkan pekerjaan. Graduan perlu menampilkan kekuatan mereka dalam resume yang akan menjadi penanda aras kepada majikan untuk menentukan kelayakan graduan dipanggil untuk temu duga. Kebolehpasaran graduan boleh dilihat melalui jumlah graduan yang mendapat tawaran temu duga kerja yang menunjukkan permintaan industri terhadap graduan. 
Kebolehpasaran graduan dalam bidang keusahawanan di UKM masih di tahap tidak memuaskan berikutan lambakan graduan yang masih gagal mendapatkan pekerjaan setelah tamat pengajian. menjalankan perniagaan semasa belajar tidak dapat melestarikan perniagaan mereka setelah tamat pengajian. Berdasarkan Laporan Kajian Pengesanan Graduan (UKM, 2021), sebanyak 12\% graduan UKM yang tidak berjaya mendapat pekerjaan selepas tamat pengajian pada tahun 2019. Statistik ini makin meningkat pada tahun 2020 apabila seramai 13.9\% daripada keseluruhan pelajar tidak mendapat pekerjaan sekaligus menjadi kebimbangan kepada pihak universiti yang telah menyumbang kepada peningkatan statistik tersebut.

Pelbagai pendekatan dan inisiatif telah dilakukan oleh pihak UKM dalam menangani isu ini termasuk mendedahkan mahasiswa dengan ilmu keusahawanan termasuk peluang bimbingan untuk menjadi usahawan dengan harapan agar mahasiswa berjaya mencipta peluang pekerjaan khususnya dalam bidang keusahawanan setelah tamat pengajian kelak. Walaupun pada peringkat awalnya, didapati bahawa bilangan mahasiswa yang menjalankan perniagaan semasa dalam tempoh pengajian semakin bertambah, namun kebanyakan mereka tidak dapat melestarikan perniagaan mereka setelah tamat pengajian. Graduan lebih cenderung untuk meneruskan kerjaya dalam bidang pengkhususan masing-masing selari dengan program pengajian yang diikuti di institusi pendidikan tinggi. Bidang keusahawanan menjadi pilihan terakhir bagi graduan untuk memastikan mereka tidak terus menganggur dan mempunyai sumber pendapatan.

Rata-rata graduan tidak mempunyai keyakinan untuk menjadikan bidang keusahawanan sebagai kerjaya utama kerana mereka tidak melihat potensi bidang keusahawanan sebagai jaminan kerjaya. Bidang ini mempunyai risiko mengalami kerugian sekiranya tidak diuruskan dengan betul. Pembangunan kemahiran keusahawanan pelajar perlu diintegrasikan ke dalam kurikulum pengajaran di universiti untuk mempersiapkan mereka dengan peluang yang lebih luas selepas graduasi. Kemahiran ini termasukkan meningkatkan kebolehan berfikir secara kreatif dan inovatif dalam menyelesaikan masalah dan berani menghadapi cabaran. Keusahawanan bukan sahaja menjadi pilihan kerjaya malah membentuk personaliti yang mempunyai jati diri yang utuh, berdaya tahan dan berdaya saing (Abdullah, 2015). Walaupun mahasiswa telah mengikuti program keusahawanan semasa dalam tempoh pengajian, hal tersebut tidak menjamin mahasiswa untuk melangsungkan perniagaan setelah tamat pengajian kelak.

Terdapat pelbagai faktor yang menyebabkan program keusahawanan yang ditawarkan di UKM kurang mendapat sambutan dalam kalangan pelajar prasiswazah. Kekangan masa dan kurang minat merupakan faktor utama yang menyumbang dalam isu ini. UKM perlu merangka dan merancang kembali program keusahawanan yang berkesan untuk memberi peluang kepada pelajar prasiswazah untuk meningkatkan kemahiran insaniah dan kemahiran keusahawanan bagi meningkatkan kebolehpasaran mereka setelah tamat pengajian. Pengalaman alumni UKM yang telah mengikuti program dan berjaya dalam perniagaan mereka perlu dijadikan panduan dengan mengambil kira keperluan pelajar untuk mempersiapkan mereka sebagai seorang usahawan. Oleh itu, satu kajian penyelidikan telah dijalankan untuk memperkasakan dan menambahbaikkan program keusahawanan di kampus dengan meninjau keberkesanan dan kesesuaian program keusahawanan yang pernah dijalankan sebelum ini dalam kalangan alumni UKM yang kini telah berjaya menjadi usahawan. Aspek utama yang perniagaan dikaji termasuklah kandungan program, penyampaian, pengendalian dan persekitaran program keusahawanan. 


\section{Sorotan Literatur}

Pembangunan modal insan merupakan perkara penting untuk menggerakkan sektor ekonomi di Malaysia kepada aktiviti berintensif pengetahuan dan inovasi sejajar dengan gagasan Pelan Tindakan Keusahawanan Institusi Pengajian Tinggi 2016-2020. Melahirkan graduan yang mempunyai minda keusahawanan memberi nilai tambah kepada graduan meningkatkan kebolehpasaran mereka ke alam pekerjaan serta bertindak sebagai penjana pekerjaan. Kajian Pengesanan Graduan yang dilaksanakan oleh Kementerian Pengajian Tinggi Malaysia menjadi panduan terhadap tahap kebolehpasaran graduan selepas mereka menamatkan pengajian. Selaras dengan wawasan 2020, kerajaan berhasrat untuk menjadikan negara ini penuh dengan masyarakat yang berciri keusahawanan yang mempunyai daya kreatif dan inovatif (Zulfakar et al., 2010). Kewujudan usahawan dalam negara dapat memajukan negara seterusnya memberi peluang pekerjaan kepada orang lain (Nasharudin \& Harun, 2010). Perkara ini dipersetujui oleh Anwar, Ahmad dan Kamaruddin (2020) dalam kajiannya yang menyatakan bahawa usahawan adalah sumber negara ke arah kecemerlangan pembangunan ekonomi.

Cabaran graduan mendapatkan pekerjaan telah sinonim pada era pembangunan teknologi yang semakin pesat. Graduan kini terpaksa menerima tawaran kerja yang tidak berkaitan dengan bidang pengajian di IPT untuk meneruskan kehidupan dan meningkatkan taraf hidup ke tahap yang stabil. Yusof et al. (2013) dalam kajiannya menjelaskan bahawa faktor utama masalah pengangguran graduan adalah disebabkan oleh kekurangan kebolehpasaran dan kebolehkerjaan graduan yang tidak memenuhi tuntutan industri atau sektor pekerjaan. Banyak faktor yang mempengaruhi kemampuan siswazah IPT untuk memenuhi kehendak pekerjaan seperti pencapaian dalam pendidikan dan latihan yang diterima dari institusi pengajian tinggi. Selain itu, aspek sikap, kemahiran dan daya pemikiran juga menyumbang kepada faktor kesukaran mendapat tawaran pekerjaan (Yussof et al., 2008). Ahmad dan Mansor (2007), pula menyatakan kebanyakan graduan memilih kursus yang menawarkan pekerjaan yang terhad.

Pelbagai inisiatif telah dilakukan untuk menangani isu pengangguran graduan Malaysia. Pada tahun 2011, program Skim Latihan 1 Malaysia telah ditubuhkan dengan tujuan untuk membantu graduan baharu mencari pekerjaan (Tamara, 2017). Melalui Majlis Amanah Rakyat (MARA), kerajaan telah membantu usahawan-usahawan baharu dengan memberi modal supaya dapat meringankan beban pada permulaan peringkat (Utusan Malaysia, 2008). Di samping itu, kerajaan bekerjasama dengan syarikat swasta dan syarikat berkaitan kerajaan untuk meningkatkan peluang kebolehpasaran graduan. Bidang keusahawanan tampil sebagai salah satu jalan penyelesaian kepada isu ini. Ratarata pelajar menganggap pendidikan keusahawanan adalah ilmu untuk belajar berniaga semata-mata. Justeru, siswazah cenderung untuk menumpukan bidang pengajian masing-masing dengan harapan memperoleh pekerjaan yang selaras dengan pengajian di IPT. Hashim dan Radio (2011) dalam kajiannya menyatakan bahawa bidang keusahawanan bukan sahaja dapat menyelesaikan pelbagai masalah malah sebagai penyumbang pekerjaan atau salah satu alat untuk menyelesaikan masalah pengangguran.

Menurut Smith (2010), aktiviti keusahawanan adalah pemangkin kepada pertumbuhan ekonomi dan bina upaya kepada usaha meningkatkan inovasi, kreativiti dan daya saing sesebuah negara. Usahawan bukan sahaja mencipta kerjaya, tetapi mencipta kerjaya 
untuk orang lain (Ali et al., 2010). Dalam kajian yang dilakukan oleh Nor Aishah (2006), lima tunjang utama menjadi asas kepada pembentukan kurikulum pendidikan keusahawanan iaitu pembentukan sikap dan ciri-ciri keusahawanan, pembentukan pemikiran keusahawanan, kemahiran pengurusan perniagaan, pembentukan vokasional dan amalan etika dan moral keusahawanan. Mohd Noor, Ooi dan Mohd Zin (2004) menyatakan bahawa pendidikan keusahawanan secara formal bertujuan untuk membentuk seorang insan yang tidak terfikir untuk menjadi usahawan sehingga insan tersebut berminat, mengenal dan memilih kerjaya tersebut.

Minda keusahawanan yang cuba diterapkan kepada pelajar pengajian tinggi adalah berbentuk dinamik, kreatif dan inovatif yang lebih luwes. Untuk mengukur kekuatan dan kelemahan sistem pendidikan keusahawanan, penilaian keberkesanan perlu dilakukan sebagai usaha memastikan kesesuaian dan ruang penambahbaikan pendidikan keusahawanan sedia ada di IPT. Menurut satu coretan teknik kejayaan analisis kes yang dilakukan oleh Brinkerhoff (2003), kajian keberkesanan yang baik perlu mendapat jawapan kepada salah satu atau kesemua empat soalan asas terdiri daripada mengetahui apa yang berlaku, hasil yang diperoleh dari pelaksanaan program, nilai kepada hasil program tersebut dan kaedah menambahbaikkan inisiatif yang diimplementasikan bagi mendapatkan kaedah penilaian yang boleh dipercayai, praktikal dan cepat.

Mahlberg (1996) menyatakan bahawa beliau bersetuju bahawa sekolah dan universiti mempunyai peranan yang penting dalam mempromosikan keusahawanan sejak institusi pengajian dianggap sebagai satu tempat yang ideal untuk membentuk budaya dan aspirasi keusahawanan dalam kalangan pelajar untuk mereka terus hidup dalam persekitaran perniagaan yang mantap pada hari ini. Persekitaran pengajaran universiti merupakan faktor yang amat mempengaruhi persepsi pelajar terhadap kerjaya keusahawanan (Autio et al., 1997). Wahid, Hashim dan Ibrahim (2017) juga bersetuju bahawa persekitaran universiti merupakan elemen penting dalam mempengaruhi niat keusahawanan dalam kalangan pelajar. Ooi et al. (2014) bersetuju bahawa persekitaran universiti memainkan peranan yang penting dalam menyediakan sumber dan lain-lain kemudahan bertujuan untuk menunjukkan imej positif usahawan seterusnya menarik perhatian pelajar supaya memilih keusahawanan sebagai kerjaya mereka. Oleh itu, pihak universiti perlu mengambil langkah yang betul dalam menarik minat pelajar ke arah keusahawanan seperti melibatkan alumni usahawan universiti sendiri.

Alumni usahawan juga memainkan peranan yang penting dalam menyokong ekosistem keusahawanan dalam sesebuah institusi pengajian. Hal ini kerana perkongsian cerita kejayaan alumni dapat dijadikan bukti tersurat bagi membentuk keyakinan pelajar terhadap bidang keusahawanan (Alias \& Ismail, 2021). Menurut kajian Alias dan Ismail (2021) juga, secara tidak langsung kejayaan alumni dapat dijadikan sandaran dan contoh oleh pelajar untuk menceburi bidang perniagaan selepas mereka bergraduat. Malah, penglibatan alumni usahawan dalam program keusahawanan dijangka dapat mempengaruhi pelajar untuk membuat keputusan menceburi perniagaan hasil daripada pendedahan awal semasa pengajian mereka.

\section{Metod Kajian}

Kajian ini menggunakan pendekatan kualitatif iaitu dengan menggunakan kaedah temu bual ke atas 15 orang informan kajian yang terdiri daripada alumni UKM. Informan kajian yang dipilih adalah merupakan graduan UKM dan pernah mengikuti program 
keusahawanan sepanjang pengajian mereka serta merupakan seorang usahawan yang sedang menjalankan perniagaan setelah tamat pengajian dari UKM. Dalam proses temu bual, soalan-soalan telah diajukan dalam bentuk pertanyaan secara 'open ended' dengan memberi tumpuan terhadap perspektif informan kajian ke atas keberkesanan program keusahawanan yang pernah disertai sepanjang pengajian di kampus termasuk kandungan program, kaedah penyampaian, impak dan pengendalian program. Temu bual dengan informan kajian dijalankan secara tidak rasmi iaitu melalui perbualan dan penceritaan pengalaman. Data juga dicerap semasa aktiviti perbincangan kumpulan terfokus 'Focus Group Discussions' (FGD) Bersama alumni usahawan.

Penyelidik berperanan sebagai moderator dalam sesi temu bual dengan memberikan soalan-soalan kepada informan kajian sejajar dengan objektif kajian yang digariskan. Soalan-soalan perbincangan merangkumi perkara seperti pengalaman informan dalam menjalani aktiviti keusahawanan semasa dalam tempoh pengajian, impak program keusahawanan kepada informan dalam memberi motivasi dan dorongan untuk memulakan perniagaan serta sumbangan yang ingin lakukan dalam memperkasakan ekosistem keusahawanan di UKM untuk mahasiswa-mahasiswi masa hadapan.

Perbincangan kumpulan terfokus yang dijalankan secara bersiri di mana alumni dipecahkan kepada 4 sesi mengikut kesesuaian masa dan kelapangan informan. Perbincangan kumpulan terfokus pusingan pertama melibatkan dua kumpulan telah diadakan pada 31 Oktober 2021, manakala pusingan kedua dan ketiga telah diadakan pada 13 November 2021 dan 18 November 2021 melibatkan 15 orang alumni usahawan UKM secara keseluruhannya. Perbincangan ini dijalankan secara dalam talian bagi menjamin keluwesan kepada informan dari segi logistik untuk menyertai sesi perbincangan yang dijalankan. Seluruh perbincangan direkodkan dan ditranskripsikan secara verbatim. Seterusnya transkrip perbincangan dianalisis dan dikategorikan mengikut tema untuk dipaparkan sebagai dapatan kajian.

\section{Dapatan Kajian}

Kajian ini dianalisis berdasarkan lima pengelasan kategori daripada maklum balas alumni usahawan UKM. Kategori tersebut ialah i) kelemahan program keusahawanan ii) penambahbaikan terhadap program keusahawanan iii) impak program keusahawanan iv) sumbangan alumni dalam program keusahawanan dan v) cadangan program keusahawanan berimpak pada masa hadapan. Rajah 1 menunjukkan peta konsep hubungan antara topik soalan perbincangan kumpulan terfokus dengan kategori yang dibentuk.

\subsection{Demografi Informan Kajian}

Berdasarkan analisis kajian, informan kajian terdiri daripada 9 orang lelaki (60\%) dan 6 orang perempuan (40\%). Dari segi komposisi umur, majoriti informan adalah berumur 21-25 tahun (40\%), diikuti oleh peringkat umur 26-30 tahun (33\%), 31-35 tahun (20\%) dan seorang daripada peringkat umur 41-45 tahun. Manakala dari segi pengelasan perniagaan yang dijalankan oleh informan kajian pula, seramai 5 orang yang menjalankan perniagaan berasaskan makanan dan minuman, 5 orang informan menjalankan lain-lain perkhidmatan seperti teknologi dan kesihatan. 3 orang informan menjalankan perusahaan percetakan baju dan 2 orang informan menjalankan perniagaan produk keperluan rumah. Alumni yang terlibat lahir daripada pelbagai fakulti seperti Fakulti Ekonomi \& Pengurusan (20\%), Fakulti Sains \& Teknologi (13.3\%), 
Fakulti Sains Kesihatan (13.3\%), Fakulti Sains Sosial \& Kemanusiaan (13.3\%), Fakulti Kejuruteraan \& Alam Bina (6.7\%), Fakulti Teknologi \& Sains Maklumat (6.7\%), Fakulti Pendidikan (6.7\%), Graduate School of Business (6.7\%), Fakulti Pengajian Islam (6.7\%) dan Fakulti Undang-Undang (6.7\%).

Rajah 1: Kerangka konsep hubungan antara soalan dengan tema yang terbentuk

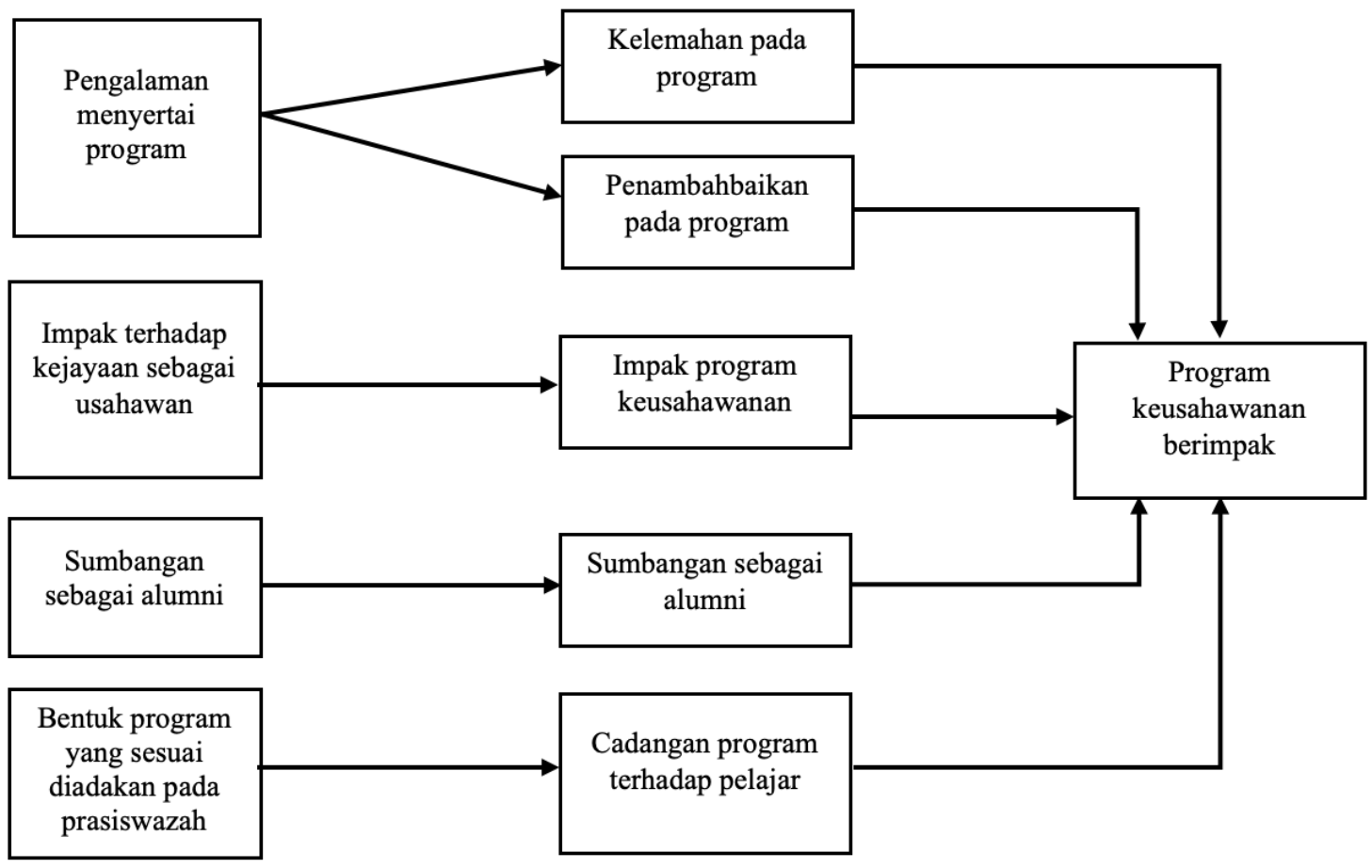

\subsection{Impak Program Keusahawanan}

Secara keseluruhannya, informan kajian menyatakan bahawa banyak program-program keusahawanan yang mereka ikuti sepanjang pengajian memberi impak yang besar kepada mereka sehingga mereka terdorong untuk menjadi usahawan. Walaupun mereka bukan daripada bidang perniagaan, mereka dapat mempelajari banyak ilmu baharu melalui program dan kursus keusahawanan tersebut. Kebanyakan peserta meluah rasa berterima kasih dan bersyukur kerana pihak UKM mengadakan program-program tersebut dan terbuka untuk semua pelajar tidak kira bidang apa pun. Justeru, programprogram keusahawanan yang pernah mereka ikuti telah menjadi batu loncatan kepada mereka dalam memajukan diri dan tidak hanya bergantung kepada bidang utama mereka sahaja.

Melalui analisis yang dijalankan, majoriti informan kajian menyatakan bahawa programprogram keusahawanan sama ada akademik atau bukan akademik banyak memberi impak positif kepada mereka sebagai usahawan pada masa kini. Walaupun ada antara informan kajian yang mengikuti program keusahawanan di luar universiti, namun perkara itu tetap membuktikan bahawa program keusahawanan memberi impak sehingga mereka termotivasi dan terdorong untuk menjadi usahawan setelah menamatkan pengajian. Mereka menyatakan bahawa program keusahawanan tersebut banyak memberi inspirasi kepada diri sendiri di samping membuka minda bahawa mereka juga dapat mencipta pekerjaan kepada komuniti selain membina perniagaan sendiri melalui bidang yang dipelajari. 


\begin{abstract}
"Kursus atau program yang diikuti ialah Kursus Instruktur Kecergasan Senamrobik dan Pengurusan Gimnasium anjuran UKM-CESMED dengan Kementerian Belia \& Sukan. Kursus ini memberi impak kerana ia sangat bagus dan pelengkap kepada apa yang saya belajar iaitu bidang pemakanan. Ia beri inspirasi untuk menambah nilai diri supaya boleh bagi inspirasi kepada orang lain." - Zarul
\end{abstract}

Informan kajian mendedahkan bahawa pengalaman sepanjang menyertai program tersebut sangat berharga. Mereka menyatakan bahawa mereka dapat melihat cara komuniti di luar negara berniaga dan mempelajari banyak input penting daripada mereka. Selain itu, mereka juga dapat berkongsi pelbagai ilmu baharu, idea dan pengalaman daripada usahawan-usahawan yang sudah berjaya dalam hidup mereka di samping menambah nilai jati diri agar mereka juga mampu memberi inspirasi kepada orang lain.

\begin{abstract}
"Saya ada menyertai Pertandingan Membina Rancangan Perniagaan anjuran UiTM di peringkat Asia. Saya suka tentang program ini kerana ia membuka minda saya tentang langkah pertama dalam berniaga. Saya boleh melihat macam mana orang luar negara (Malaysia) berniaga." Shira
\end{abstract}

Pelbagai persepsi daripada informan kajian mengenai pengalaman mereka. Ada antara informan yang menyatakan bahawa ketika beliau mengikuti kelas akademik keusahawanan, beliau langsung tidak terfikir bahawa akan membuka perniagaan sendiri. Hasil kajian mendapati bahawa program keusahawanan memainkan peranan yang penting dalam kehidupan alumni usahawan UKM kerana di samping meningkatkan ilmu dan memupuk minat, ia juga dapat meningkatkan keyakinan dalam diri di mana bahawa semua orang juga boleh berniaga walaupun bukan daripada bidang perniagaan. Hal ini kerana, kebanyakan informan yang mengikuti program pengajian di UKM bukanlah dalam bidang perniagaan. Apabila mereka pertama kali menyertai kursus keusahawanan, minat mereka semakin bertambah dan ingin menyertai kursus-kursus keusahawanan yang lain.

\title{
4.3. Kelemahan Program Keusahawanan
}

Hasil kajian mendapati bahawa walaupun program-program keusahawanan banyak memberi impak kepada informan kajian, masih terdapat kelemahan pada program yang perlu ditambahbaikkan. Hal ini kerana kebanyakan peserta mengatakan bahawa kelemahan pada program yang mereka sertai perlu diambil kira oleh pihak universiti bagi memantapkan lagi program keusahawanan selain meningkatkan sambutan pelajar terhadap program keusahawanan tersebut.

Analisis mendapati bahawa hebahan mengenai program keusahawanan masih kurang di fakulti dan kolej sekaligus mengurangkan keterlihatan atau 'visibility' dalam kalangan mahasiswa di kampus. Hal ini kerana walaupun informan tersebut daripada fakulti di kampus Bangi, mereka mengatakan bahawa hebahan program di fakulti dan kolej masih lemah. Pihak penganjur perlu meningkatkan hebahan tersebut untuk mendapatkan sambutan yang tinggi daripada pelajar terutamanya pelajar yang berada di kampus Jalan Raja Muda dan kampus Cheras Kuala Lumpur. 


\begin{abstract}
"Pendedahan tentang aktiviti-aktiviti dan program-program keusahawanan anjuran UKM-CESMED kurang di fakulti saya (FSSK)..." Faris
\end{abstract}

"Hebahan berkenaan aktiviti keusahawanan di setiap fakulti agak kurang dan kami tidak tahu apa program keusahawanan yang sedang berjalan atau akan dilaksanakan"- Din

Di samping itu, beberapa orang informan kajian mengatakan bahawa terdapat kursus atau program keusahawanan yang mereka sertai terlalu fokus kepada ilmu teori berbanding praktikal. Hal ini demikian kerana pelajar kini lebih suka belajar melalui praktikal (psikomotor) berbanding teori semata-mata. Mereka berpendapat bahawa jika penyampaian kursus tersebut lebih kreatif, pelajar mungkin lebih memahami maklumat yang ingin disampaikan.

\begin{abstract}
"Apa yang saya tidak suka dengan program ini adalah kandungannya terlalu asas dan umum untuk usahawan, ia lebih baik jika program ini lebih khusus kepada satu-satu bidang seperti kemahiran pemasaran dan sebagainya."- Izzat

"Apa yang saya tidak suka ialah dari segi penyampaian kerana penyampaian sesetengah penceramah terlalu mendatar dan menyebabkan peserta menjadi bosan. Penyampaian perlu kreatif dan perlu ditambah baik."- Mai
\end{abstract}

Selain itu, hasil kajian mendapati, kebanyakan informan kajian menzahirkan rasa ketidakpuasan hati dengan jemputan usahawan tamu yang tidak mempunyai kaitan dengan universiti. Hal ini demikian kerana ada program yang menjemput usahawan yang bukan alumni sendiri. Maklumat yang dikongsi oleh usahawan tersebut tidak dapat difahami sepenuhnya oleh pelajar kerana pengalaman usahawan tersebut semasa dalam pengajian adalah jauh berbeza dengan mahasiswa-mahasiswi UKM. Informan kajian berpendapat bahawa pelajar tidak mendapat input yang sepatutnya kerana usahawan tersebut tidak merasai pengalaman yang sama seperti apa pelajar sedang tempuhi. Malah, kebanyakan pelajar UKM tidak dapat mengaitkan cabaran yang ditempuhi oleh usahawan jemputan tersebut semasa memulakan perniagaan sejak dalam kampus.

"Apa yang saya tidak boleh ikut ialah ada satu program motivasi yang menjemput usahawan luar seperti tidak berkaitan dengan pelajar UKM".Sabri

Seterusnya, bimbingan dan didikan terhadap pelajar untuk menceburi bidang keusahawanan masih lemah. Hasil kajian mendapati, informan kajian mengatakan bahawa pelajar tidak memahami sepenuhnya motif mereka menyertai kursus keusahawanan walaupun idea mereka sangat menarik. Menurut informan kajian, program susulan selepas program keusahawanan tidak diberi perhatian oleh pihak pengurusan menyebabkan pelajar tidak mempunyai tempat rujukan untuk meneruskan kelangsungan idea perniagaan yang ingin diterjemahkan kepada perniagaan sebenar.

"Program hanya dalam jangka masa pendek dan pelajar tidak ada tempat rujukan selepas tamat program. Kebanyakan pelajar terpaksa 
mencari alternatif sendiri untuk meneruskan idea perniagaan mereka"Mai

“...susulan selepas program tidak diberi perhatian dan ini amat merugikan banyak pihak"- Raja

\subsection{Penambahbaikan Terhadap Program atau Kursus}

Dalam usaha untuk meningkatkan sambutan pelajar terhadap program atau kursus keusahawanan, penambahbaikan perlu dilakukan. Hasil kajian mendapati, antara penambahbaikan yang perlu dilakukan ialah meningkatkan hebahan tentang pusat keusahawanan universiti (UKM-CESMED) dan program ke setiap fakulti dan kolej. Kebanyakan informan mengatakan bahawa pihak UKM-CESMED perlu memberi pendedahan yang menyeluruh kepada pelajar agar pelajar menyedari kewujudan UKMCESMED dan program-program yang dilaksanakan. Analisis mendapati informan mengatakan bahawa perlunya kerjasama dengan persatuan pelajar di fakulti dan kolej untuk meningkatkan hebahan mengenai program tersebut.

"Bekerjasama dengan persatuan-persatuan di kolej untuk memberi kesedaran kepada pelajar tentang UKM-CESMED dahulu." - Suzi

"Pendapat saya, UKM-CESMED perlu adakan program yang sangat besar dan bekerjasama dengan alumni yang berjaya dan berkempen secara besar-besaran seperti pilihanraya. Boleh juga bekerjasama dengan persatuan dan badan kepimpinan kolej." - Sabri

Selain itu, hasil kajian mendapati penambahbaikan yang boleh dilakukan ialah program tersebut perlu dilakukan dalam jangka masa panjang atau mempunyai susulan dan pemantauan berkala daripada mentor terhadap pelajar selepas tamat program atau kursus keusahawanan. Ini bertujuan untuk menyediakan ruang sebagai tempat rujukan atau mentor kepada pelajar untuk bimbingan dan sokongan dalam bidang keusahawanan. Informan kajian mengatakan bahawa pelajar akan berasa bersemangat dan mempunyai motivasi untuk terus menceburi bidang perniagaan jika mempunyai mentor yang dapat membimbing mereka dan sistem sokongan keusahawanan yang mantap dan lestari.

\section{"Program keusahawanan perlu menekankan peranan mentor-mentee dan boleh libatkan alumni usahawan" - Izwan \\ "Kumpulkan pelajar dalam minat atau bidang yang sama boleh menjadi mentor kepada kumpulan tersebut." - Izwan}

Seterusnya, berdasarkan analisis kajian, terdapat informan yang mencadangkan supaya pihak penganjur perlu libatkan alumni usahawan untuk memberi perkongsian kepada para pelajar. Ini kerana pelajar akan mendapat input yang amat bersesuaian terutamanya jika alumni tersebut pernah merasai pengalaman yang sama seperti pelajar. Malah, mereka boleh menjadikan input tersebut sebagai inspirasi kepada perusahaan mereka di masa akan datang. Mereka percaya bahawa perkongsian daripada alumni usahawan lebih memberi motivasi kepada pelajar berbanding usahawan bukan alumi. 
"Lebih baik pihak penganjur menjemput alumni UKM yang menjadi usahawan barulah input lagi masuk dan terkesan kepada pelajar." - Sabri

“...perlu jemput semula usahawan dari universiti sendiri supaya pelajar merasa berada dalam kasut yang sama." - Shira

Di samping itu, pihak universiti perlu memberi fokus yang lebih kepada pelajar yang mempunyai minat dan ingin menjalankan perniagaan. Hasil kajian mendapati bahawa informan mengatakan program yang dianjurkan perlu fokus kepada pelajar yang ingin berniaga sahaja supaya dapat meningkatkan kualiti usahawan pelajar. Hal ini adalah untuk mengelakkan pihak penganjur membuang masa, tenaga dan wang ringgit kerana terlalu fokus kepada pelajar lain yang sememangnya tidak mahu melibatkan diri dengan keusahawanan. Tambahan lagi, untuk mengubah minda seseorang adalah sangat sukar dan banyak cabaran yang perlu dihadapi selain memberikan dorongan dan motivasi agar minda usahawan dapat diperkembangkan menjadi tingkah laku usahawan.

"Fokus kepada pelajar yang ingin berniaga/ menjadi usahawan sahaja" Izzat

“...perlu membuat tapisan kualiti dan kuantiti yang seimbang sekurangkurangnya pelajar perlu mempunyai niat untuk berniaga" - Aidil

\subsection{Sumbangan Sebagai Alumni Usahawan}

Hasil kajian mendapati secara keseluruhannya, informan berminat untuk memberi sumbangan sebagai alumni usahawan. Mereka menyatakan hasrat dan kesudian jika dijemput untuk memberi perkongsian kepada para mahasiswa UKM. Setiap informan kajian mempunyai pelbagai kepakaran yang berbeza untuk disumbangkan bagi melahirkan ramai usahawan dalam kalangan pelajar.

"Saya boleh sumbangkan perkara tentang 'marketing' dan 'branding'. Content writing, copy writing and how to develop something digitally, photoshop, adobe illustrator..."-Sal

"Social entrepreneurship...hanya asas untuk orang lain faham apa itu keusahawanan sosial kerana ia berbeza dengan bisnes yang lain." - Wani

Terdapat informan yang sudi untuk memberi peluang kepada pelajar untuk menjalankan program tindikan usahawan bagi membantu mereka merasai pengalaman berniaga.

"Boleh menjadi pembekal kepada pelajar untuk menjual produk keropok ikan. Membantu pelajar supaya pelajar dapat menjual sambil belajar." Aidil

"Saya boleh tawarkan pelajar untuk membuat sangkutan (internship) keusahawanan di syarikat saya" - Izwan

Secara keseluruhannya, alumni usahawan UKM sentiasa berminat untuk membantu pelajar-mahasiswa-mahasiswi yang sedang mengikuti pengajian dalam kampus untuk memahami dan menceburi bidang keusahawanan. Menurut mereka, ini adalah salah 
satu sumbangan untuk membalas balik jasa pihak universiti dan UKM-CESMED yang banyak membantu mereka semasa mereka bergelar pelajar sehingga mencipta nama sebagai usahawan berjaya masa kini.

\subsection{Cadangan Program Keusahawanan di Masa Akan Datang}

Hasil kajian mendapati, beberapa cadangan program keusahawanan terhadap pelajar prasiswazah dapat dikenal pasti untuk penambahbaikan pada masa akan datang. Antara cadangannya ialah mengadakan program mentor-mentee bersama alumni usahawan UKM sendiri. Para alumni boleh menjadi mentor kepada pelajar untuk membimbing mereka dalam bidang keusahawanan mengikut bidang masing-masing. Program yang diadakan juga perlu dalam jangka masa yang panjang supaya pelajar merasai keseronokan dalam berniaga.

Selain itu, program tersebut juga perlu memfokuskan kepada pelajar yang ingin menjalankan perniagaan sahaja supaya tidak berlaku pembaziran masa, tenaga dan wang ringgit. Walaupun program tersebut sudah tamat, pelajar tersebut perlu dipantau secara berkala supaya mereka sentiasa bersemangat dan mempunyai motivasi yang tinggi dalam membudayakan keusahawanan.

"Cadangan saya, kita mengadakan program untuk 3 fasa. Fasa pertama, bagi pendedahan keusahawanan kepada pelajar sekurang-kurang 2 hari (expose). Fasa kedua, beri ruang kepada pelajar tersebut untuk meneroka sendiri perusahaan tersebut (explore). Sangat penting untuk mendekatkan pelajar dengan usahawan mengikut bidang. Contohnya, menjadi agen atau 'dropship'. Fasa ketiga iaitu pengalaman (experience). Mereka perlu merasai pengalaman sendiri seperti melabur duit sendiri, merancang dan melangsungkan perniagaan. Pelajar cukup berada dalam industri hanya untuk membina jaringan sendiri dan belajar selok belok industri sebelum jalankan perniagaan sendiri. Jadi, dalam masa 4 tahun, mereka akan mendapatkan ilmu bagaimana untuk mencari dana dan rancangan perniagaan di akhir program." - Raja

"Program tersebut perlu bersifat program jangka panjang sekurangkurangnya setahun. Contohnya, Program 'Sportspreneur'di mana peserta perlu didedahkan dengan bengkel kemahiran sukan selama 2 hari. Selepas itu, bawa pelajar masuk ke industri seperti kesihatan untuk tujuan Latihan dan praktikal. Dekatkan mereka dengan syarikat kecergasan dan akhir sekali, mereka dapat menjadi pelatih." - Zarul

Secara keseluruhannya, perkara yang ditekankan oleh informan dalam melaksanakan program dalam kalangan pelajar ialah dengan mendedahkan pelajar dengan keusahawanan melalui pengalaman, praktikal dan menjalankan sendiri perusahaan di samping didikan oleh mentor yang berterusan.

\section{Kesimpulan}

Penglibatan pelajar dalam program keusahawanan perlu digalakkan oleh setiap institusi pengajian tinggi bagi memperkasakan bidang keusahawanan dalam negara sekaligus mengurangkan isu pengangguran graduan. Program-program keusahawanan di universiti sangat bermanfaat untuk pelajar agar mereka tidak terlalu bergantung kepada 
bidang utama mereka dalam membina kerjaya. Hal ini demikian kerana kebanyakan pelajar yang terlibat dalam program-program tersebut mendapat pelbagai ilmu dan kemahiran seperti kemahiran insaniah, kemahiran keusahawanan disamping meningkatkan keyakinan diri dan membentuk jaringan sesama mereka. Jaringan antara usahawan seperti keluarga, rakan, pembekal, kerajaan dan lain-lain dapat memberi sokongan dari segi sumber, maklumat, sokongan dan peluang kepada pelajar usahawan (Hamed \& Deraman, 2002).

Oleh yang demikian, inisiatif kerjasama antara pihak universiti dan alumni usahawan amat diperlukan dalam meningkatkan sambutan pelajar terhadap bidang keusahawanan selain memperkasakan ekosistem keusahawanan dalam kampus. Kerjasama yang terbentuk antara pihak universiti dan alumni usahawan merupakan satu pendekatan yang inovatif dalam pemerkasaan kandungan program keusahawanan yang lebih sesuai dan mengikut era semasa kepada pelajar. Pelajar cenderung untuk lebih mendengar nasihat daripada alumni berbanding pensyarah kerana bagi mereka, alumni mempunyai pengalaman yang sama seperti mereka selain jurang umur/ generasi yang tidak jauh berbanding pensyarah. Justeru itu, kajian ini mendapati bahawa sokongan semua pihak dan persekitaran dalam universiti yang lestari dalam memperkasakan landskap keusahawanan mampu meningkatkan sambutan pelajar terhadap program keusahawanan di masa akan datang.

\section{Penghargaan (Acknowledgement)}

Terima kasih kepada responden yang terlibat secara langsung dan telah memberikan kerjasama dalam menjayakan kajian ini. Terima kasih juga kepada kakitangan UKMCESMED dan Pusat Pembangunan Karier UKM yang turut membantu secara tidak langsung bagi melicinkan pelaksanaan kajian ini.

\section{Kewangan (Funding)}

Kajian ini telah dibiayai menggunakan Geran Galakan Pengurusan \& Profesional (GGPP2020-010).

\section{Konflik Kepentingan (Conflict of Interests)}

Para penulis tidak mempunyai konflik kepentingan terhadap kajian ini.

\section{Rujukan}

Abdullah, M, S. (2015). Faktor - Faktor Yang Mempengaruhi Pelajar - Pelajar Diploma Kejuruteraan Politeknik Dalam Menceburi Bidang Keusahawanan. Laporan Projek. Universiti Tun Hussien Onn Malaysia.

Ahmad, R., \& Mansor, N. N. (2012). Proses Kognitif, Pembuatan Keputusan Dan Pemilihan Kerjaya. Kajian Emperikal Menggunakan Perspektif Peta Kognitif. Jurnal Kemanusiaan, 10(2).

Ali, H., Abdul Razak, N., \& Ahmad, S. (2010). Faktor mempengaruhi kejayaan usahawan peruncitan Melayu: satu kajian kes. Persidangan Kebangsaan Ekonomi Malaysia ke V (PERKEM V), Port Dickson, Negeri Sembilan, 15-17. 
Alias, H., \& Ismail, A. (2021). Pembangunan Atribut Keusahawanan Dalam Kalangan Pelajar Kolej Vokasional Kpm: Sasaran Dan Strategi Pelaksanaan. JuPiDi: Jurnal Kepimpinan Pendidikan, 8(3), 18-37.

Anwar, M., Ahmad, N., \& Kamaruddin, N. (2020). Faktor Pendorong Pelajar UTHM Dalam Bidang Keusahawanan. Kajian Kes Di Malaysia, 45-52.

Autio, E., Keeley, R. H., Klofsten, M., \& Ulfstedt, T. (1997). Entrepreneurial intent among students: Testing an intent model in Asia, Scandinavia and USA. Frontiers of Entrepreneurship Research, 17: Babson College/Kauffman Entrepreneurship Research Conference, Centre for Entrepreneurial Studies, Babson College, Wellesley.

Brinkerhoff, R. (2003). The Success Case Method: Find Out Quickly What's Working and What's Not. Berrett- Koehler Publishers.

Hamed, A. B., \& Deraman, N. (2002). Jaringan usahawan: Satu pengenalan. Jelapang, 3(1), 91-94. http://drotspss.blogspot.my/2011/02/tajuk-57-kajian-keberkesanansesuatu.html. Akses pada 8 April 2020.

Hashim, S. \& Radio, N. (2011). Ciri Personaliti Keusahawanan Pelajar Tahun 2 SPH Fakulti Pendidikan. Tesis Sarjana Muda. Universiti Teknologi Malaysia Skudai, Johor.

Mahlberg, T. (1996). Evaluating secondary school and college level entrepreneurial education - pilot testing questionnaire. The Internationalising Entrepreneurship Education and Training Conference. Arnhem/University of Nijmegen, The Netherlands.

Mohd Noor, M.S., Ooi, Y.K., \& Mohd Zin, M. (2004). Kecenderungan keusahawanan: Satu kajian empirikal di kalangan tenaga akademik Politeknik-politeknik Malaysia. International of Management Studies, 11(2), 171-194.

Nasharudin, N. \& Harun, H., (2010). Aspirasi Kerjaya Keusahawanan dalam Kalangan Pelajar Institusi Pengajian Tinggi Awam. Jurnal Pendidikan Malaysia, 35(1), 11-17.

Nor Aishah, B. (2006). Asas Keusahawanan. Shah Alam: Penerbit Fajar Bakti Sdn. Bhd.

Ooi, Y. K., Ahmad, S., Bakar, H., \& Hashim, N. (2014). Pengajaran keusahawanan sebagai kursus wajib: satu kajian empirikal di Universiti Utara Malaysia. Jurnal Pendidikan Bitara UPSI, 7, 29-40.

Smith, D. (2010). The role of entrepreneurship in economic growth. Undergraduate Economic Review, 6(1), 1-18.

Tamara, J. (2017, Mei 30). Memiliki Ijazah tetapi masih mengggur. Diambil daripada: https://leaderonomics.com/bm/artikel/sl1m-graduan-menganggur

Universiti Kebangsaan Malaysia. (2021). Laporan Kajian Pengesanan Graduan 2021.

Utusan Malaysia (2008). Kerjasama lahirkan usahawan teknologi CCTV. 22 Januari 2008. Dicapai pada 13/1/2022 di http://www.utusanonline.com

Wahid, A., Hashim, N., \& Ibrahim, A. (2017). Hubungan persekitaran universiti terhadap niat keusahawanan dalam kalangan pelajar keusahawanan. Journal of Global Business and Social Entrepreneurship (GBSE), 1(1), 136-149.

Yusof, N., Jamaluddin, Z., \& Lazim, N. M. (2013). Persepsi Pelajar Prasiswazah Terhadap Kebolehpasaran Graduan Dan Persaingan Dalam Pasaran Pekerjaan. Malaysian Journal on Student Advancement, 16.

Yussof, I., Ismail, R., \& Sidin, R. (2008). Graduan dan Alam Pekerjaan: Kes Siswazah UKM (Graduates and Employment: The Case of UKM's Graduates). Akademika, 72(1).

Zulfakar, I., Buang, N. \& Halim, L. (2010). Ciri-ciri Tahap Pemikiran Sains keusahawanan dan Kesediaan Integrasi Pemikiran Sains Keusahawanan dalam Proses Pengajaran Guru-Guru Sains di MRSM. Prosiding Seminar Penyelididkan Siswazah UKM; 1(4). Fakulti Pendidikan, UKM. Bangi. 